\title{
Carbon Dioxide Embolism Following Veress Needle Insertion Into the Liver During Laparoscopic Adrenalectomy
}

\author{
Jonathan B. Yuval, MD, Katya Chapchay, MD, Haggi Mazeh, MD \\ Department of Surgery, Hadassah-Hebrew University Medical Center, Jerusalem, Israel (all authors).
}

\begin{abstract}
Although rare, complications can arise during the establishment of pneumoperitoneum during laparoscopic surgery. These include injury to blood vessels, hollow viscera, solid organs, and $\mathrm{CO}_{2}$ embolism.

We report a case of trauma to the liver following the insertion of a Veress needle causing $\mathrm{CO}_{2}$ embolism during laparoscopic adrenalectomy. Opening pressures on insertion were high. Respiratory and cardiovascular changes alerted the anesthesiologists to the possibility of $\mathrm{CO}_{2}$ embolism. The patient was treated with inotropic drugs, placed in Durant's position, and the operation was aborted. Ultrasound demonstrated gas bubbles within the liver parenchyma and the heart chambers. The patient was transferred to the surgical intensive care unit where she experienced a grand mal seizure. She was later taken to a nearby hospital for hyperbaric oxygen therapy during which she suffered 3 additional seizures. She had subsequent resolution of all neurological symptoms.

The first entry into the peritoneum deserves the full attention of the operating room team, because this is when most $\mathrm{CO}_{2}$ embolisms occur. The team should be prepared to take immediate action on suspicion of embolism. Gas embolism can occur not only by direct cannulation of blood vessels, but also by injury to solid organs, especially the liver. All overweight patients should be suspected of having hepatomegaly and the location of initial entry into the peritoneum should shift accordingly. In selected patients, one should use a direct visualization approach, because this approach has fewer complications and they are more readily identified.
\end{abstract}

Key Words: Adrenalectomy, Carbon dioxide, Embolism, Laparoscopy, Liver.

Citation Yuval JB, Chapchay K, Mazeh H. Carbon dioxide embolism following veress needle insertion into the liver during laparoscopic adrenalectomy. CRSLS e2014.00236. DOI: 10.4293/CRSLS.2014.00236.

Copyright (C) 2014 SLS This is an open-access article distributed under the terms of the Creative Commons Attribution-Noncommercial-ShareAlike 3.0 Unported license, which permits unrestricted noncommercial use, distribution, and reproduction in any medium, provided the original author and source are credited.

Address correspondence to: Haggi Mazeh, MD, Department of Surgery, Hadassah University Hospital Mount Scopus, POB 24035, Jerusalem 91240, Israel. Telephone: +972-2-5844550, Fax: + 972-2-5844584, E-mail: hmazeh@hadassah.org.il

\section{INTRODUCTION}

Laparoscopy has become the surgical method of choice for treatment of most benign abdominal pathology, including pathology of the adrenal glands. ${ }^{1}$ As with any laparoscopic procedure, a key step is the establishment of pneumoperitoneum that may be obtained via direct visualization (open) or closed approach. ${ }^{2}$ The closed approach involves blind insertion of the Veress needle into the peritoneum followed by $\mathrm{CO}_{2}$ insufflation and trocar insertion. Although complications are rare in both approaches, some investigators have stated that the incidence of blood vessels and viscera injury is more common in the closed approach using a Veress needle than it is in the direct visualization approach (0\% vs $0.048 \%$ and $0.083 \%$ vs $0.075 \%$, respectively). ${ }^{3}$ Other investigators claim similar complication rates in both approaches. ${ }^{2,4,5}$ Carbon dioxide $\left(\mathrm{CO}_{2}\right)$ embolism has been reported in $0.0014 \%$ to $0.6 \%$ of cases ${ }^{3}$ and the clinical consequences of $\mathrm{CO}_{2}$ embolism range from asymptomatic changes in $\mathrm{CO}_{2}$ to significant morbidity that includes cerebral ischemia or death. ${ }^{6-8}$

Solid organ injury during the establishment of pneumoperitoneum in laparoscopic procedures is extremely rare or at least rarely reported. ${ }^{1,8}$ Reports on $\mathrm{CO}_{2}$ embolism secondary to solid organ injury are also scarce. ${ }^{9}$ We report a case of trauma to the liver during the insertion of a 
Veress needle causing $\mathrm{CO}_{2}$ embolism during laparoscopic adrenalectomy. The patient suffered transient neurological deficit, which resolved completely. A worse outcome in this case was avoided by early diagnosis and treatment in the operating room as well as subsequent hyperbaric oxygen therapy.

\section{CASE REPORT}

A 68-year-old woman with past medical history significant for hypothyroidism, hypertension, and hyperlipidemia was admitted for elective laparoscopic right adrenalectomy for Cushing's syndrome. Her preoperative evaluation included symptoms, signs, and laboratory tests consistent with Cushing's adenoma. She complained of weight gain, weakness, sleep disturbances, and facial hair. Her physical examination was positive for moon face, buffalo hump, central obesity, striae, and hirsutism. Laboratory evaluation revealed hyperlipidemia and impaired fasting glucose. Dexamethasone did not suppress cortisol levels and adrenocorticotropic hormone levels were low. Urine analysis was negative for metanephrines. Computerized tomography revealed a $46-\mathrm{mm}$ tumor in the right adrenal gland and a $16-\mathrm{mm}$ tumor in the left gland. Functional imaging demonstrated right-sided activity with no activity of the left adrenal. Following multidisciplinary team discussion, laparoscopic right adrenalectomy was recommended.

In the operating room, general anesthesia was induced by $200 \mathrm{mg}$ of intravenous propofol and endotracheal intubation was performed. General anesthesia was maintained by sevoflurane. For analgesia, the patient received $100 \mu \mathrm{g}$ of fentanyl on induction and subsequent remifentanil drip at a rate of $0.1 \mu \mathrm{g} / \mathrm{kg} / \mathrm{min}$. The patient was placed in the left lateral decubitus position. A Veress needle was inserted in the right upper quadrant of the abdomen 1 fingerbreadth below the right costal line, and high-flow intraperitoneal $\mathrm{CO}_{2}$ insufflation was initiated. During insertion, aspiration of the Veress needle was not attempted. The opening pressure was $12 \mathrm{~mm} \mathrm{Hg}$ and therefore the Veress needle was removed. Immediately, the end tidal $\mathrm{CO}_{2}$ dropped from 39 to $17 \mathrm{~mm} \mathrm{Hg}$, and the oxygen saturation slightly decreased from $98 \%$ to $96 \%$. This was followed by an increase in heart rate from 60 to 95 beats per minute while blood pressures plummeted from $130 / 60$ to $60 / 40$ $\mathrm{mm} \mathrm{Hg}$. Following these events, the anesthesiologist informed the surgeons of the changes and $\mathrm{CO}_{2}$ embolism was suspected. $\mathrm{FiO}_{2}$ was increased to $100 \%$. Then $10 \mathrm{mg}$ of ephedrine and $0.5 \mathrm{mg}$ of epinephrine were administered intravenously. The patient was simultaneously placed in the Trendelenburg position, and she rapidly recovered. An intraoperative echocardiogram was performed, and small air emboli were identified in all the heart chambers. Abdominal ultrasound revealed gas bubbles within the liver parenchyma. Despite the rapid recovery, the operation was aborted due to the severity of the previous deterioration.

The patient was extubated and was taken to the surgical intensive care unit in stable condition, fully alert, and with no neurological deficit. The following day, the patient developed a grand mal seizure accompanied by left hemiparesis. Brain computerized tomography was normal and phenytoin therapy was initiated. The patient was transferred to a nearby hospital for hyperbaric treatment. She received 5 hours of hyperbaric treatment and experienced 3 more short seizure episodes during this time. Following hyperbaric treatment, hemiparesis spontaneously resolved, and no more seizures occurred. The patient was discharged in good overall medical condition.

\section{DISCUSSION}

Establishing pneumoperitoneum is a key step in laparoscopic surgery. Although rare, there are some complications associated with both the direct visualization and closed techniques of establishing pneumoperitoneum. These include, in descending order, injury to blood vessels, injury to hollow viscera, and injury to solid organs. Gas embolism can occur when a $\mathrm{CO}_{2}$ is iatrogenically injected into the bloodstream or into an organ. ${ }^{8}$ Pressure-related entry of gas into the venous plexus has also been proposed as a possible etiology for gas embolism. ${ }^{7}$

Gas embolism is associated with several complications. The severity of the complications depends on the balance between the volume of $\mathrm{CO}_{2}$ entering circulation and the amount of gas that is removed. ${ }^{10} \mathrm{~A}$ small gas embolism may be clinically inconsequential because $\mathrm{CO}_{2}$ is highly soluble in the blood. ${ }^{11}$ Larger emboli may cause clinically significant and severe complications. $\mathrm{CO}_{2}$ bubbles may cause a gas plug in the vena cava, right atrium, or right ventricular outflow tract, thus decreasing preload and diminishing cardiac output. Gas emboli can also enter pulmonary circulation causing ventilation to perfusion mismatch and hypoxemias or pulmonary edema. Additionally, $\mathrm{CO}_{2}$ emboli may paradoxically enter systemic arterial circulation, thus causing myocardial or cerebral ischemia. ${ }^{12}$ 
In the case report, we indicated that gas embolism was caused by direct $\mathrm{CO}_{2}$ injection to the liver as later confirmed by abdominal ultrasound. The embolism was also demonstrated in all heart chambers by echocardiography in the operating room. In response to the early suspicion, the following actions were taken in the operating room: $\mathrm{FiO} 2$ was increased to $100 \%$, inotropic drugs were administered, and the patient was placed in left lateral Trendelenburg position. The patient later developed neurological signs of cerebral ischemia including generalized seizures and hemiparesis. She was transferred to a hyperbaric chamber and her symptoms later resolved.

A level of suspicion for gas embolism should always accompany the entry of the first trocar or Veress needle in laparoscopy. In fact, $60 \%$ of symptomatic gas embolisms occur during insufflation. ${ }^{6}$ Signs of trauma to organs or blood vessels are not always immediately obvious to the surgeon. There is also some evidence that gas embolism is less likely with a direct visualization approach. ${ }^{3}$ This complication may be reduced by using a direct visualization approach when feasible. When a closed approach is used, it is recommended to aspirate the Veress needle and reposition the needle before insufflation if blood or stool are extracted. ${ }^{10}$ It is possible that gas embolism could have been avoided in this case by using this simple measure.

Signs of hypercarbia and hypoxemia should alert the operating room team that a gas embolism may have occurred. Initial increases in end tidal $\mathrm{CO}_{2}$ may change to hypocarbia due to ensuing cardiovascular collapse and ventilation perfusion mismatch. Additionally, a precipitous drop in the patient's blood pressure can be indicative of a venous gas plug. Intraoperative echocardiogram may help with the diagnosis. A mill-wheel murmur may be heard as well. ${ }^{6}$

Immediate treatment should include deflation of the peritoneum, placement of the patient in the Durant (left lateral Trendelenburg) position, ventilation with 100\% oxygen, and aggressive cardiovascular resuscitation. Some investigators advocate the insertion of a central line for aspiration of gas, but this depends on the position of the catheter relative to the embolus and may not be practical or very effective. ${ }^{12}$ If there is clinical evidence of paradoxical arterial embolization, hyperbaric oxygen therapy is indicated. ${ }^{12}$ By giving 100\% oxygen at pressures above sea level, one can achieve very high plasma partial pressures of oxygen causing a substantial diffusion gradient for gas to exit the bubbles. Additionally, this treatment enhances oxygen delivery to tissues. ${ }^{12}$
A few lessons may be learned by our experience with this patient. Insufflation of gas following the entry of the first trocar or Veress needle into the peritoneum deserves the full attention of the whole operating room team. The team should be prepared to take immediate action on suspicion of gas embolism. Although the most common mechanism for gas embolism in laparoscopy is due to direct cannulation of blood vessels, embolism may occur with injection of gas into a solid organ, particularly the liver. This may be because the hepatic veins do not collapse as most systemic veins do. ${ }^{13}$ Overweight patients, like the patient described, should be suspected of having hepatomegaly. In these patients in particular, but perhaps in all patients, the placement of the Veress needle should be more caudal and medial. Although some investigators have stated that very little information is attained by Veress needle safety tests, ${ }^{5}$ we believe aspiration of the Veress needle should always be attempted in closed access of pneumoperitoneum. Aspiration may help avoid substantial morbidity and causes no significant complications. Lastly, when possible, it is safer to use a direct visualization approach not only to avoid entry into viscera or blood vessels but also to quickly discern evidence of any such damage.

\section{References:}

1. Azevedo JL, Azevedo OC, Miyahira SA, et al. Injuries caused by Veress needle insertion for creation of pneumoperitoneum: a systematic literature review. Surg Endosc. 2009; 23(7):1428-1432.

2. Perunovic RM, Scepanovic RP, Stevanovic PD, Ceranic MS. Complications during the establishment of laparoscopic pneumoperitoneum. J Laparoendosc Adv Surg Tech A. 2009;19(1): $1-6$.

3. Bonjer HJ, Hazebroek EJ, Kazemier G, Giuffrida MC, Meijer WS, Lange JF. Open versus closed establishment of pneumoperitoneum in laparoscopic surgery. Br J Surg. 1997;84(5): 599-602.

4. Woolcott R. The safety of laparoscopy performed by direct trocar insertion and carbon dioxide insufflation under vision. Aust N Z J Obstet Gynaecol. 1997;37(2):216-219.

5. Vilos GA, Ternamian A, Dempster J, Laberge PY, The Society of Obstetricians and Gynaecologists of Canada. Laparoscopic entry: a review of techniques, technologies, and complications [in English, French]. J Obstet Gynaecol Can. 2007;29(5):433-465.

6. Gutt CN, Oniu T, Mehrabi A, et al. Circulatory and respiratory complications of carbon dioxide insufflation. Dig Surg. 2004;21(2):95-105. 
7. Blaser A, Rosset P. Fatal carbon dioxide embolism as an unreported complication of retroperitoneoscopy. Surg Endosc. 1999;13(7):713-714.

8. Park EY, Kwon JY, Kim KJ. Carbon dioxide embolism during laparoscopic surgery. Yonsei Med J. 2012;53(3):459466.

9. Zikry AA, Desousa K, Alanezi KH. Carbon dioxide embolism during laparoscopic sleeve gastrectomy. J Anaesthesiol Clin Pharmacol. 2011;27(2):262-265.

10. Yau P, Watson DI, Lafullarde T, Jamieson GG. Experimental study of effect of embolism of different laparoscopy insuf- flation gases. J Laparoendosc Adv Surg Tech A. 2000;10(4): 211-216.

11. Lam A, Kaufman Y, Khong SY, Liew A, Ford S, Condous G. Dealing with complications in laparoscopy. Best Pract Res Clin Obstet Gynaecol. 2009;23(5):631-646.

12. Muth CM, Shank ES. Gas embolism. N Engl J Med. 2000; 342(7):476-482.

13. Kjeld T, Hansen EG, Holler NG, Rottensten H, Hyldegaard O, Jansen EC. Resuscitation by hyperbaric exposure from a venous gas emboli following laparoscopic surgery. Scand J Trauma Resusc Emerg Med. 2012;20:51 